\title{
GÉNERO Y LENGUAJE. PRESUPUESTOS PARA UN LENGUAJE JURÍDICO IGUALITARIO
}

\author{
POR \\ MARÍA LUISA BALAGUER CALLEJÓN \\ Catedrática de Derecho Constitucional \\ Consejera del Consejo Consultivo de Andalucía
}

\section{Consideraciones metodológicas previas}

Este trabajo pretende indagar en las posibilidades del desarrollo de la perspectiva de género en el lenguaje. En él se es consciente de las dificultades actuales de incardinación del lenguaje de género en el actual ordenamiento jurídico y de su necesaria graduación. El lenguaje jurídico exige la mayor posibilidad de correspondencia de significados, para evitar la inseguridad del tráfico jurídico, y es necesario por tanto, que las expresiones lingüísticas se aproximen en la mayor medida a la justa expresión que se pretende en su regulación. Sin embargo, es posible modificar el género en el derecho, si en lugar de pensar todo esto desde el derecho, intentamos aproximarnos al lenguaje. Aquí encontraremos muchos argumentos de justificación de la necesidad del lenguaje de género, dada la relación entre pensamiento y lenguaje, y también algunas posibilidades de superación del masculino genérico, sin incurrir en el despilfarro lingüístico de que se acusa al lenguaje dualista.

El estudio del lenguaje de género es relativamente reciente en las ciencias sociales, y como probablemente la totalidad de los estudios de género, se encuentra en los inicios de su formulación ${ }^{1}$. Ello no implica, mas bien al contrario,

${ }^{1}$ La lingüística, como ciencia del lenguaje, es relativamente reciente. Corresponde a F. Saussure la formulación y el intento de sistematización de una ciencia del lenguaje. Saussure dis- 
que podamos vislumbrar un ámbito reducido en el objeto de los estudios de género, sino muy al contrario, estamos ante un amplio campo de investigación, que además nos obligará a una concepción interdisciplinar ${ }^{2}$. Es muy importante tener en cuenta esto, porque como veremos, muchas de las objeciones que se hacen al lenguaje de género, parten de una consideración netamente lingüística, que abunda en el masculino genérico, como opción identificativa del conjunto de las mujeres y los hombres, intentan justificar como innecesario el avance a una concepción binaria del lenguaje, y además pretenden basarse en las insoslayables dificultades técnicas de un lenguaje de género.

Sin embargo, desde la propia concepción científica de la lingüística, y desde el buen uso de la técnica jurídica, se hace necesaria la implantación del lenguaje de género. Esto se desprende, no solamente de la necesidad de identificación de cada objeto con su denominación propia, que desde un punto de vista formal, justificaría esa exigencia de correspondencia o identidad, sino porque desde ambas posiciones científicas, hay una clara concepción de la importancia del lenguaje en la determinación del pensamiento. Esta concepción impone que la identidad de las mujeres, como sujeto diferenciado de los varones, merezca su propia consideración en el lenguaje.

\section{EL LENGUAJE}

\section{La filosofía del lenguaje}

La correspondencia o identidad entre un objeto y su designación está presente ya en Platón, aún cuando no sea hasta principios del pasado siglo cuándo

tingue entre lengua como sistema de expresiones, habla, como uso individual del sistema, lingüística sincrónica que estudia la constitución y funcionamiento del sistema y lingüística diacrónica, que estudia la evolución. Saussure ha formulado la ciencia lingüística en los términos en que hoy la conocemos. La lengua es una parte del lenguaje, es una convención, y el signo otra. Es la parte social del lenguaje que existe en virtud de un contrato establecido entre los miembros de la comunidad. Como tal sistema de signos que expresan ideas, es susceptible de estudio científico y debe ser parte de la psicología social, de la general por tanto, y se llamaría semiológica (estudio de los signos y las leyes que los gobiernan). F. de Saussure, "Curso de lingüística general». Edit. Losada. S.A. Madrid, 2002, pág. 60. De ahí que no vea la semiótica como una ciencia autónoma sino vinculada necesariamente a la psicología.

${ }^{2}$ En este sentido se pronuncia D. Tannen, que considera los estudios de género en el ámbito interdisciplinar de la sociolingüística, por la necesaria relación entre la lengua y los "fenómenos sociales». Además, la antropología, en la medida en que es necesario tener en cuenta el "contexto cultural». En Género y discurso, Edit. Paidós. Barcelona, 1996, pág. 17. 
se haya desarrollado la lingüística en términos de significante y significado. Pero ya en el siglo XVIII el estado científico de la filología, permitía afirmar el papel activo de la mente en la comprensión del lenguaje, y desde el siglo XIX, los estudios comparados de la filología mostraban diferencias significativas del lenguaje en función de las capacidades mentales de los sujetos. El Círculo de Lingüistas de Praga afirmará con Jackobson el papel activo de la mente en la comprensión del lenguaje. Quién escucha no se limita a registrar pasivamente los elementos que se le transmiten sino que elabora y recrea los contenidos.

Esta idea, cuyo origen está en los iniciales planteamientos de Humboldt acerca de la influencia recíproca entre lenguaje y pensamiento ${ }^{3}$, dará lugar a nuevas formas de concepción de la filosofía, basadas en la importancia del lenguaje como base de la estructura mental con la que el sujeto configura su pensamiento ${ }^{4}$. Este "giro lingüístico" tiene sus antecedentes en una concepción de la filosofía y, por extensión del mundo y de la vida, que considera indiciariamente que la vida es energía que se mueve y esta teoría de la vida conduce a una teoría del lenguaje ${ }^{5}$.

Se inicia ahí lo que se ha llamado el "giro lingüístico», un verdadero cambio de paradigma en la filosofía. Desde esta concepción, el conocimiento tiene un límite que es el lenguaje. En su Prólogo al «Tractatus» Wittgenstein explica la intención de su libro: «lo que siquiera puede ser dicho, puede ser dicho claramente; y de lo que no se puede hablar, es mejor callar» ${ }^{7}$. Ese límite

3 W. vOn Humboldt, Sobre la diversidad de la estructura del lenguaje humano. Edit. Anthropos, Barcelona, 1990, pág. 57. Considera el autor que el lenguaje «no se limita a una existencia pasiva, de simple recepción de impresiones, sino que, de entre la infinita diversidad de las posibles direcciones del intelecto, el lenguaje se guía por una determinada, y en virtud de su propia actividad interna modifica a su vez toda influencia que le llega de fuera.»

${ }^{4}$ Sobre la influencia del lenguaje en el pensamiento W. vON HumbOLDT, Sobre la diversidad de la estructura del lenguaje humano. Edit. Anthropos, Barcelona, 1990, pág. 58, para quién «existe una conexión indudable entre la estructura de la lengua y todas las demás modalidades de actividad intelectual.»

5 «Vivir significa mantener dominante, como ley, una forma de pensamiento en una masa de materia por medio de una fuerza misteriosa... y generar significa hacer empezar a aquella fuerza misteriosa... encender una fuerza que de repente arranca de la masa cierta cantidad de materia en una forma completamente determinada, y a partir de ahora opone continuamente una forma en su peculiaridad a todas las otras formas». W. V. HumbOLDT, Escritos de filosofia de la historia. Tecnos. Madrid, pág. 44.

6 Sobre algunas peculiaridades del origen del "giro lingüístico», J. HABERMAS, La ética del discurso y la cuestión de la verdad. Edit. Paidós. Barcelona, 2003, pág. 69.

7 «El libro quiere, pues, trazar un límite al pensar, o mas bien, no al pensar, sino a la expresión de los pensamientos: porque para trazar un límite al pensar tendríamos que poder pensar am- 
hay que trazarlo en el lenguaje ${ }^{8}$. El lenguaje es lo que permite comprender el mundo?.

En congruencia con estos planteamientos de Wittgenstein y otros autores, Gadamer elabora una teoría de la interpretación, que nos descubre la relación entre el lenguaje y el pensamiento como una unidad interna, en la que el sujeto vierte sus concepciones propias ${ }^{10}$ adquiridas en otros procesos previos de conocimiento $^{11}$. Lo que permite al sujeto conocer su historia, está también en el lenguaje $^{12}$, y ello es así, porque sólo a través del lenguaje somos capaces de conocer la realidad que nos rodea ${ }^{13}$. Lo que convierte al lenguaje en el instrumento imprescindible para crear la Historia e interpretarla ${ }^{14}$. En suma, para Gadamer la concepción del mundo está intermediada por las posibilidades que ofrece el lenguaje $^{15}$.

Gadamer heredará de Heiddeger, Derrida y otros la búsqueda de la ruptura con las restricciones constructivas a través de las cuales el lenguaje se hace dueño

bos lados de este límite (tendríamos, en suma, que poder pensar lo que no resulta pensable)». L. Wittgenstein, Tractatus Lógico-Philosophicus. Alianza Universidad. Madrid, 1993, pág. 11.

8 Ib., pág. 49 punto 4, «El pensamiento es la proposición con sentido», consideración que reitera en el punto 4001 cuándo dice que «la totalidad de las proposiciones es el lenguaje». Y en el 4.03, que reduce igualmente la filosofía a la lengua: "toda filosofía es critica lingüística», pág. 49.

9 Esto es así a tal punto que Wittgenstein dirá que «los límites de mi lenguaje significan los límites de mi mundo». Ib. Punto 5.6, pág. 143. de ahí el punto 7 y último párrafo de su obra, «de lo que no se puede hablar hay que callar».

${ }^{10}$ H. GadAmer, Verdad y método. Edit. Paidós. Barcelona. «Querer evitar los propios conceptos en la interpretación no solo es imposible sino que es un absurdo evidente. Interpretar significa justamente aportar los propios conceptos previos con el fin de que la referencia del texto se haga realmente lenguaje para nosotros», pág. 476.

11 «El que vive en un lenguaje esta penetrado de la insuperable adecuación de las palabras que usa para las cosas a las que se refiere». Ib., pág. 482.

12 «Es la experiencia del «tu» en el terreno hermenéutico. En la medida en que ese reconocimiento pretende elevarse entero por encima de su propio condicionamiento, queda aprisionado en la dialéctica, porque lo que realmente quiere es hacerse dueño del pasado. La historia acaba no siendo otra cosa que una experiencia hermenéutica, lo que nos remite necesariamente a la función del lenguaje». «Verdad y método», pág. 437.

13 «El lenguaje es el medio universal en el que se realiza la comprensión misma. La forma de realización de la compresión es la interpretación». Ib., pág. 467.

14 «La forma lingüística y el contenido trasmitido no pueden separarse en la experiencia hermenéutica. Si cada lengua es una acepción del mundo, no lo es tanto en su calidad de representante de un determinado tipo de lengua sino en virtud de aquello que se ha hablado y transmitido en ella». Ib., pág. 529.

15 «El verdadero significado del lenguaje para la hermenéutica se encuentra en su descubrimiento de la acepción del lenguaje como acepción del mundo». Ib., pág. 531. 
del pensamiento. Parte de la propia etimología del «logos» para relacionar la filosofía con el lenguaje ${ }^{16}$, y fija en Platón algunas de las consecuencias posteriores de ésta relación ${ }^{17}$.

La filosofía del lenguaje considera que toda experiencia está mediada por la relación entre el pensamiento y el lenguaje ${ }^{18}$. Este nuevo paradigma otorga al lenguaje un carácter definitivo en la formación del pensamiento ${ }^{19}$. A partir de esa formulación, la filosofía no cuestionará esta predeterminación del pensamiento ${ }^{20}$.

Desde esta concepción del lenguaje, se puede afirmar que «La lengua es el producto social de cada uno depositado en el cerebro $»^{21}$. De ahí se desprende el papel activo que el lenguaje tiene en la configuración del pensamiento ${ }^{22}$. Y por lo tanto, la relación entre el nombre de cada cosa y su significación ${ }^{23}$.

16 Para relacionar la filosofía con el lenguaje acude a la etimología griega de «logos». Para los griegos el lenguaje es antes que nada lo que en el se dice, «logos», no es un sistema de signos sino mas bien el concepto por excelencia de los conocimientos humanos, reflejados en el lenguaje y transmitidos a través del lenguaje. Ib., pág. 175.

17 En este momento indiciario del estudio del lenguaje lo que si sabemos con certeza es que «la adecuación de la palabra sólo podrá juzgarse desde el conocimiento de las cosas», pág. 489. Según Gadamer Platón no reflexiona todavía sobre el hecho de que la realización del pensamiento, concebida como diálogo del alma, implica a su vez una vinculación al lenguaje.

${ }^{18}$ En Estética y hermética, Gadamer volverá a considerar el lenguaje como «el medio universal de la experiencia». Edit. Tecnos. Madrid, 1986, pág. 19.

${ }_{19}$ Los conceptos que pensamos, ya han pensado siempre por nosotros. La conceptualización en la que intentamos prender nuestros pensamientos, marca de antemano y predetermina lo que podamos asir desde nuestra propia experiencia del pensar. Ib., pág. 186.

20 «Las actividades mentales solo se manifiestan a través del lenguaje.» H. Arendt. «La vida del espíritu». Edit. Paidos. Barcelona, 2002, pág. 120.

${ }^{21}$ F. DE SAUSSURE, op. cit., pág. 71. Y por lo tanto, «lo que el signo lingüístico une no es una cosa y un nombre, sino un concepto y una imagen acústica. La imagen acústica no es el sonido material, cosa puramente física, sino su huella psíquica, la representación que de él nos da el testimonio de nuestros sentidos; esa imagen es sensorial, y si llegamos a llamarlo «material» es solamente en este sentido y por oposición al otro término de la asociación, el concepto, generalmente, mas abstracto». Ib., pág. 134.

22 «El signo lingüístico es pues una entidad psíquica de dos caras, concepto e imagen acústica, a cuya combinación llamamos signo. Este signo engloba ahora el significante y el significado». Ib., pág. 134.

${ }^{23}$ W. von Humboldt, Sobre la diversidad de la estructura del lenguaje humano. Edit. Anthropos, Barcelona, 1990, pág. 60, «la peculiaridad espiritual y la conformación lingüística de un 


\section{La filología y el lenguaje}

Es fundamental, en esta nueva concepción del lenguaje, la implicación de sectores del conocimiento científico que desborda el ámbito puramente lingüístico y filosófico. En este sentido se impone una concepción del lenguaje desde la Sociología del lenguaje, la etnografía, e incluso el psicoanálisis. El lenguaje se configura en este sentido como el medio fundamental de la expresión de la producción simbólica inherente a la naturaleza humana.

El planteamiento de Saussure desde la lingüística se corresponde con la concepción del lenguaje desde la filosofía a lo largo de todo el siglo XX. La formulación de Wittgenstein de que el pensamiento es un paso intermedio entre el mundo y el lenguaje, representa en el fondo la misma idea en Saussure de que la cuestión epistemológica deriva de la cuestión lingüística ${ }^{24}$. El pensamiento solo es posible definirlo en términos de lenguaje, como proposición con sentido ${ }^{25}$. A partir de esta idea, la función del lenguaje es la de abrir el mundo ${ }^{26}$.

Al conocimiento del mundo se accede a través del lenguaje, lo que confiere al lenguaje la capacidad de formulación del pensamiento ${ }^{27}$. De ahí la importancia de otras ciencias, no humanistas en relación con los estudios del lengua-

pueblo están tan estrechamente fundidas la una con la otra, que si estuviese dada la una, la otra debería poder derivarse íntegramente de ella»... el lenguaje es, puede decirse, la manifestación externa del espíritu de los pueblos.

${ }^{24}$ Sabemos desde la publicación del Tractatus, que «El pensamiento es la figura lógica de los hechos». (4.002), «intermediario figurativo esencial entre una realidad pensada y unos signos lingüísticos pensados, asimismo, que de éstos un modelo o figura de aquella». J. MUÑOZ e ISIDORO REGUERA, Introducción al Tractatus, pág. XVII.

${ }^{25}$ Es una idea ya presente en Humboldt al considerar que «la lengua forma conceptos, introduce en la vida el dominio del pensamiento». W. VON HUMBOLDT, Escritos sobre el lenguaje. Edit. Península. Barcelona, 1991, pág. 114.

26 J. HABERMAS, Verdad y justificación. Edit. Trotta, Madrid, 2002. El lenguaje tiene una fuerza estructurante para las creencias, las acciones y las expresiones comunicativas en tres niveles: articulación lingüística del horizonte del mundo de la vida, nivel de la praxis del entendimiento dentro de este mundo de la vida interusbjetivamente compartido, nivel de mundo objetivo entendido como totalidad de las entiddes sobre las que se dice algo, y que los participantes en la comunicación formalmente presumen. Es en el nivel medio donde se produce la interacción entre apertura de mundo y procesos de aprendizaje intramundanos. Ello no solamente nos permite ver lo que nos encontramos en el mundo bajo determinados aspecto y puntos de vista sino como partes de una totalidad estructurada categorialmente, págs. 126-7.

27 «El habla es un rasgo básico, el rasgo básico de la capacidad lingüística humana. El sistema que regula el lenguaje tiene como funciones básicas las de transmitir, comprender y almacenar información y pensar usando las palabras». A. Puente Ferreras, Los orígenes del lenguaje. Edit. Alianza, Madrid, 2006, pág. 294. 
je, como la biología ${ }^{28}$, que indague acerca de la configuración física del lenguaje en áreas concretas de los hemisferios ${ }^{29}$.

Chomsky ha formulado, desde una posición que arranca en parte de las teorías de Humboldt ${ }^{30}$ acerca de la vitalidad del lenguaje ${ }^{31}$, lo que se ha conocido como "gramática generativa»" ${ }^{32}$, planteando nuevas posibilidades acerca del lugar exacto en el que podría localizarse físicamente la capacidad de desarrollar el lenguaje, y ha indicado como es posible la consideración del lenguaje como un producto social ${ }^{33}$. De hecho, hay en Chomsky una llamada metodológica a la interdisciplinariedad en la construcción de la mente, como exigencia del conocimiento de todo lo que queda por averiguar en ese campo científico. Debe avanzarse a su juicio en los aspectos mentales del mundo ${ }^{34}$, incluyendo el lenguaje humano, y en la construcción de cuerpos de doctrina interdisciplinares hasta llegar a la unificación ${ }^{35}$.

Chomsky piensa que puede existir una estructura neurológica que abarque el órgano del lenguaje ${ }^{36}$. Contradice la idea de Piaget de que la mente se desarrolla

${ }^{28}$ Las evidencias neurobiológicas sugieren que los lingüistas deberían considerar un enfoque con una motivación biológica, que caracterice a las operaciones mentales que usan los seres humanos para comprender el lenguaje por medio de procesos distribuidos y paralelos semejantes a los que regulan el control motor. Ib., pág. 297.

29 «El conocimiento lingüístico es el conocimiento del mundo exterior, almacenado en el cerebro en forma de palabras a las que se accede a través de los sonidos del habla humana. Y el habla interior es un medio del pensamiento humano». Ib., pág. 294.

30 Hay una conexión muy importante entre las teorías de Chomsky, y la idea de Humboldt de que «Se debe considerar la lengua no tanto como un producto inerte sino sobre todo como una producción».W. VON HUMBOLDT, Sobre la diversidad de la estructura del lenguaje humano. Edit. Anthropos, Barcelona, 1990, pág. 63.

31 «La lengua misma no es una obra (ergon) sino una actividad (energeia). Por eso su verdadera definición no puede ser sino genética». W. VON HUMBOLDT, Sobre la diversidad de la estructura del lenguaje humano. Edit. Anthropos, Barcelona, 1990, pág. 65.

32 Entiende que el lenguaje "genera» un conjunto infinito de expresiones, y proporciona instrucciones a los diversos sistemas de actuación por eso a la teoría del lenguaje la llama «gramática generativa». N. CHOMSKY, La arquitectura del lenguaje. Edit. Kairos. Barcelona, 2003, pág. 23.

33 «Los estudiosos del lenguaje y de la adquisición del lenguaje que creen que el lenguaje es un estado del cerebro, han omitido una posibilidad importante y es que el lenguaje esta fuera del cerebro, es un organismo extrahumano que ha evolucionado. La ciencia cognitiva ha evolucionado también a las consideraciones del lenguaje como un producto social». CHOMSKY y otros. «La mente y el resto de la naturaleza». En El lenguaje y la mente humana. Edi. Ariel. Barcelona, 2002, págs. 174-175.

34 «El lenguaje es el órgano que forma la idea».W. vON HumbOLDT, Sobre la diversidad de la estructura del lenguaje humano. Edit. Anthropos. Barcelona, 1990, pág. 74.

35 Ib., pág. 178.

${ }^{36}$ Considera que "la gramática universal es la suma total de todos los principios inmutables que la herencia genética construye en el órgano del lenguaje. Estos principios abarcan la gramática, 
como conjunto, no como estructura modular con capacidades específicas que se van desarrollando cada cual a su manera ${ }^{37}$.

La gramática generativa cambiará la concepción del lenguaje en el sentido de considerar que, más que un espejo de la mente, el lenguaje es un componente esencial de la mente humana ${ }^{38}$. Ello obliga a indagar en el conocimiento de esa mente $^{39}$, en la medida en que el lenguaje siempre tiene algo de especulativo ${ }^{40}$. Es mediante el lenguaje cómo intentamos indagar en el pensamiento de la otra persona, intentando conocer su estado mental, a la vez que exteriorizamos nuestro propio pensamiento ${ }^{41}$.

\section{La antropología y el lenguaje}

La sociología del lenguaje estudia los problemas sociopolíticos que generan las relaciones entre lenguas distintas que coexisten de un modo u otro en una comunidad. Entre estos problemas se encuentran las políticas lingüísticas y acciones y procesos de planificación lingüística. Se definen las políticas lingüísticas como los objetivos diseñados por poderes públicos o civiles para influir sobre el

la fonética y la semántica. Por decirlo de otro modo, la gramática universal es la dotación genéticamente heredada que nos posibilita hablar y aprender distintas lenguas humanas.» N. CHOMSKY, Escritos sobre democracia y educación. Edit. Paidós. Barcelona, 2005, pág. 75.

37 «El uso normal del lenguaje no consiste en el ejercicio del hábito o destreza de algunos. Por lo general el uso del lenguaje es creativo, en el sentido de que implica constantemente la producción e interpretación de formas nuevas: nuevas en la experiencia del hablante e incluso en la historia del lenguaje». Ib., pág. 100.

${ }^{38}$ El problema central que acompaña a todo esfuerzo hermenéutico es que a pesar de todo esfuerzo por reconocer la otredad como otredad, al otro como otro, se da demasiada importancia a la comunicación y al acuerdo. H. GADAMER, El giro hermenéutico. Edit. Cátedra. Madrid, 2001, pág. 78.

39 «El lenguaje es un espejo de la mente, es un tópico tradicional mas bien parece que el lenguaje es un componente esencial de la mente humana». Ib., pág. 104.

${ }^{40}$ El lenguaje tiene algo de especulativo, no solo en el sentido hegeliano de la prefiguración instintiva de las relaciones lógicas de la reflexión, sino como realización de sentido, como acontecer del hablar, de entenderse, del comprender. Esta realización es especulativa en cuánto que las posibilidades finitas de la palabra están en función de una orientación hacia el infinito. Especulativo significa que el lenguaje está al servicio del descubrimiento del sentido de la conversación. Permite la comprensión. H. GADAMER, Verdad y método, pág. 565.

${ }_{41}$ Nuestro grado de certeza respecto al exterior depende del lenguaje. Al revés, nuestra falta de seguridad al adscribir estados mentales a los demás es parte integrante del juego del lenguaje. El lenguaje es algo externo. L. WitTGEnstein, Últimos escritos sobre filosofía de la Psicología. Edit. Tecnos. Madrid, 1996, pág. XI. 
estatuto de las lenguas en los diversos niveles educativos, en el empleo, en áreas científicas y productivas. Supone pues, una intervención activa y sistemática a favor de una lengua.

La relación entre las teorías del conocimiento y el lenguaje, da por sentado en la actualidad que los procesos cognitivos tienen su origen en el pensamiento simbólico ${ }^{42}$.

También desde el psicoanálisis se ha planteado la relación entre lenguaje y pensamiento ${ }^{43}$, atribuyéndole un importante papel en la formación del inconsciente. En la medida en que la comunicación se concibe por el psicoanálisis como una señal, la decodificación de sus contenidos exige un papel activo en su proceso de intelección ${ }^{44}$. El lenguaje se percibe por el psicoanálisis como un modo de comunicación ${ }^{45}$ cuyo significado muestra la relación con el subconsciente, y crea una relación de identificaciones simbólicas, capaces de relacionar al sujeto con el mundo ${ }^{46}$.

No hay inconsciente sin lenguaje, porque es este el que predetermina el pensamiento ${ }^{47}$. De ahí que algunos psicoanalistas, como Lacan, consideren la inca-

42 «La cognición es el procesamiento de la información y su programación intelectual: o sea la capacidad para conceptualizar y pensar simbólicamente. En estos procesos, las diferencias se refieren a modos distintos de organizar percepciones y el conocimiento de la realidad socio-cultural, es decir, de representar las relaciones sociales y las cosas». M. J. BuXó REY, Antropología de la mujer. Anthropos. Barcelona, 1988, pág. 38.

${ }^{43}$ J. Lacan estudia la relación entre Freud y Saussure y el Círculo de Praga. A su juicio, éstos establecen en la lingüística una relación entre el significante y el significado sin precedentes en la lingüística. Saussure genera a Jackobson, que produce una teoría más acabada de estos conceptos. Sería deseable para él que un día se unieran la lingüística, la etnología y el psicoanálisis. Pues la condición para que haya inconsciente es el lenguaje. La unión entre el psicoanálisis y el lenguaje proviene de la metáfora y la metonimia, que se producen en la cadena del significante. Esto exigiría un estudio interdisciplinar que agrupara todas estas ciencias. Psicoanálisis. Radiofonía y televisión. Edit. Anagrama. Barcelona, 1977.

${ }^{44}$ En una relación profesional, hablante y oyente están permanentemente conducidos por un código, en el que el psicoanalista debe analizar el inconsciente a través del lenguaje. J. LACAN, $E_{s-}$ critos, op. cit., 448.

45 «La comunicación del lenguaje se concibe como una señal, en la que el emisor informa al receptor de algo por medio de cierto código». Ib., pág. 285.

$46 \mathrm{El}$ psicoanalista introduce la distinción significante-significado y ejecuta con las dos redes ciertas relaciones que no se recubren. El significante es la estructura sincrónica del material del lenguaje en cuanto que cada elemento toma en ella su empleo exacto por ser diferente de los otros. Y el significado es el conjunto diacrónico de los discursos efectivamente pronunciados. Aquí lo que domina es la unidad de significación lo que remite siempre a otra significación. Ib., pág. 397.

${ }^{47}$ El lenguaje es una cadena de identificaciones simbólicas. La experiencia es sobre todo lenguaje, que se comunica. El inconsciente se da a conocer en el lenguaje. Ib., pág. 448. 
pacidad de una total comunicación como consecuencia de los límites del lenguaje. Las obstrucciones a esa comunicación forman parte esencial del lenguaje. Al lenguaje es consustancial su limitación. Si no podemos llegar a un conocimiento total de nuestra mente es porque el lenguaje no nos lo permite ${ }^{48}$.

La característica del lenguaje, en relación con cualquier otro contenido simbólico, está en la necesaria sucesión en el tiempo de los sonidos que produce para hacerse inteligible ${ }^{49}$. Tal configuración crea un orden lógico en la percepción, diferente de la música, la pintura, o cualquier otro sistema de comunicación, que obliga al pensamiento a ser discursivo, por la propia exigencia del lenguaje. Esta sucesión condiciona que el lenguaje sea el lazo entre la representación y la reflexión ${ }^{50}$. El entrecruzamiento entre el pensamiento y el lenguaje, articulado en las frases que produce la sucesión de las palabras, crea los contenidos mentales en cada sujeto.

\section{El lenguaje y la dominación social}

La evolución de los estudios sobre el lenguaje sexista va paralela a la de la sociolingüística, en la medida en que esta estudia el lenguaje de los grupos en relación con su identidad cultural. A las categorías de clase social o etnias, sucede en la década de los sesenta del pasado siglo, el estudio de la categoría de género en el lenguaje ${ }^{51}$. Y al estudiar las relaciones entre lenguaje, pensamiento y realidad, se constató la infravaloración y degradación de que era objeto la mujer también en el lenguaje. El uso del masculino genérico expresaba claramente el do-

${ }^{48}$ Esta idea estaba ya presente en Humboldt cuándo consideraba que el nexo que une pensamiento y lenguaje, la actividad subjetiva, forma en el pensamiento un objeto. W. VON HUMBOLDT, Sobre la diversidad de la estructura del lenguaje humano. Edit. Anthropos. Barcelona, 1990, pág. 76. El lenguaje ya para Humboldt es la condición de la intersubjetividad, los sujetos intercambian sus percepciones y pensamientos a través del lenguaje, y solo de éste, es por tanto la condición de la intersubjetividad.

49 «Lo que distingue al lenguaje de todos los demás signos y le permite desempeñar un papel decisivo en la representación, no es tanto que sea individual o colectivo, natural o arbitrario, sino que analice la representación según un orden necesariamente sucesivo». M. FOUCAULT, Las palabras y las cosas. Edit. Siglo XXI. Madrid, 1997, pág. 87.

${ }^{50}$ Ib., pág. 88.

51 «Las diferencias lingüísticas expresadas en el comportamiento individual son una función de la estructura de la sociedad. Estas diferencias son susceptibles de manifestación como diferencias entre hombres y mujeres, tanto como pueden ser la expresión de clan o etnicidad». M. Jesús BuxÓ, Antropología de la mujer, op. cit., pág. 9. 
minio simbólico de la mujer a través del lenguaje ${ }^{52}$. Esto constituía una forma de negación de la mujer como sujeto, en la medida en que sólo era nombrada indirectamente, por intermediación del género masculino, que también la comprendía a ella. Los usos y costumbres de la sociedad son determinantes de la posición de poder de las mujeres, y condicionan asimismo sus posibilidades de desarrollo intelectual ${ }^{53}$.

«Masculino no marcado» quiere decir que en español para todo sustantivo, que es masculino o femenino desde el punto de vista gramatical, la forma masculina prevalece siempre que deba concordar una unidad lingüística cuyo género no esté marcado de modo inherente o cuando concurren ambos géneros gramaticales ${ }^{54}$. En todas las lenguas se encuentra una tendencia a llenar de simbolizaciones sexuales los elementos naturales de la experiencia ${ }^{55}$. Y a su vez determina la organización de la diferencia sexual de la manera en que hoy se representan en la mayoría de los idiomas que conocemos ${ }^{56}$.

Ahora bien, la lengua no es en sí misma sexista, sino el uso que de ella se hace ${ }^{57}$. La mayor parte del sexismo es social ${ }^{58}$. Y esto parece ser un hecho universal $^{59}$.

52 Para P. ViOLI, «el lenguaje es precisamente el lugar donde se organizan, bajo forma de códigos sociales, la creación simbólica individual, la subjetividad de las personas, estructurándose en representaciones colectivas que serán a su vez, las que determinen y formen la imagen que cada persona individual constituye de sí misma y de la propia experiencia. La relación es circular, en el lenguaje se codifican las representaciones colectivas de lo femenino, que las mismas mujeres reproducirán en la construcción de su propia imagen, imagen que a su vez tendrá que actuar de acuerdo a los códigos sociales». En El infinito singular. Feminismos. Edit. Cátedra. Madrid, 1991, pág. 36.

53 Esta idea está ya en el propio Humboldt que considera que «el carácter de la mujer depende sobre todo del tipo de relaciones familiares imperante en una nación». W. v. HUMBOLDT, Los límites de la acción del Estado. Edit. Tecnos. Madrid, 2002, pág. 32.

54 D. SuARDiAZ, El sexismo en la lengua española. Edit. Libros Pórtico. Zaragoza, 2002, pág. 151.

55 P. Violi, op. cit., pág. 62.

56 Ib., pág. 67.

57 Los estudios lingüísticos que se desarrollan ya en las siguientes décadas, pondrán de relieve aspectos importantes del sexismo en la lengua, como los de A. García Meseguer, quién afirma que la lengua española no es en si misma sexista, sino el uso que se hace de ella. «El sexismo radica en el hablante o en el oyente pero no en la lengua». En ¿Es sexista la lengua española?. Edit. Paidós. Barcelona, 1996, pág. 17.

${ }^{58}$ Distingue entre sexismo lingüístico y sexismo social. El sexismo lingüístico es en el que se incurre cuando se emplean vocablos o se construyen oraciones que debido a la forma de expresión escogida por el hablante y no por otra razón, resultan discriminatorias por razón del sexo. Y el sexismo social en el que se incurre cuando lo que se describe es un hecho sexista. Ib., pág. 25.

59 Para García Meseguer parece claro por fin que el androcentrismo es universal en el len- 
La atribución histórica en prácticamente todas las sociedades de un lenguaje genérico masculino para la designación indistinta de mujeres y hombres tiene una consecuencia inmediata, que es la conformación del universo simbólico mediada por el masculino genérico ${ }^{60}$. Y produce el falso conocimiento de que la realidad ocurre solamente en uno de los géneros, el masculino ${ }^{61}$. Esa falsedad social es consecuencia de la formación histórica de una estructura de dominación, en la que el lenguaje coadyuva al sistema de dominación patriarcal.

El estudio de la relación entre poder y lenguaje nos permite comprender la manera en que el lenguaje masculino se ha impuesto como genérico ${ }^{62}$. $\mathrm{Y}$ en la medida en que ningún sujeto se da en el vacío, sino siempre en una interrelación con otros sujetos, y dentro de las construcciones culturales tejidas en su entorno, las mujeres han de enfrentarse a una identidad preconstituida por los hombres ${ }^{63}$.

$\mathrm{Si}$ entendemos que el lenguaje se desarrolla en un modelo de dominación (patriarcado) estaremos en condiciones de abordar la deconstrucción de este modelo. Y si es a través del lenguaje como se puede perpetuar ideológicamente esa dominación, podremos entender la necesidad de utilizar la perspectiva de género en el lenguaje como uno de los modos de reconstrucción de esa dominación ${ }^{64}$. Y esto no solamente desde la consideración del masculino genérico, tema que hoy nos ocupa, sino desde concepciones más amplias del lenguaje como instrumento del patriarcado.

Es en la interacción del lenguaje donde se crean importantes estructuras de dominación social ${ }^{65}$. Y aquí es donde se pone de manifiesto la asimetría de las

guaje, el inglés incluido. El autor había asegurado en 1977 que el idioma inglés no era sexista, pero más tarde cambia de criterio y considera que es aun más sexista que el español. Ib., pág. 67.

${ }^{60}$ Uso «pseudo-genérico» del masculino, lo llaman A. GODDARD y L. M. PATTERSON, Lenguaje y género. Edit. Universidad de Castilla-La Mancha. Cuenca, 2005, pág. 9.

61 Para García Meseguer, la identificación genero gramatical-sexo es una rutina cultural, no una ley lingüística, op. cit., pág. 241.

${ }^{62} \mathrm{D}$. Tannen ha señalado como hay quiénes creen erróneamente que abordar como diferencias culturales las diferencias de género en los modos de hablar, implica que los hombres no dominan a las mujeres, sino que únicamente no las comprenden. Muy al contrario, señala la autora, que en el lenguaje, las diferencias de estilo operan en detrimento de los miembros de grupos estigmatizados y a favor de quienes tienen el poder para imponer sus interpretaciones, op. cit., pág. 19-20.

${ }^{63}$ P. Violi, op. cit., pág. 138.

${ }^{64}$ Esto crea el problema de la ausencia de la mujer como sujeto. En cuánto que todo sujeto es masculino, la mujer ha de adoptar la posición extraña a la condición de sujeto social. P. VIOLI, op. cit., pág. 145 .

65 Los enfoques sociolingüísticos actuales mantienen que las relaciones de dominación se crean sobre todo en la interacción social, que tiene lugar a través del lenguaje. Aquí se actualizan los roles sociales, y se dota de significado al lenguaje, que en sí mismo no lo tiene, sino que se produce 
mujeres y los hombres en la sociedad. Esto se puede observar, no solamente en el lenguaje escrito, sino en la interacción social del lenguaje, en el que se produce una parte importante de la dominación de género. El hombre, en la medida en que es emisor del lenguaje, sitúa a la mujer en el objeto de su dominio. La detentación de la sabiduría por parte de los hombres, los convierte en oradores, y a las mujeres en oyentes, receptores de ese mensaje ${ }^{66}$.

Otra cuestión es la de qué hacer para cambiar la supeditación de la mujer al lenguaje masculino. En este sentido las posiciones no son coincidentes a menudo con el análisis. Hay quiénes piensan que la erradicación del lenguaje sexista no necesita más que esperar a la igualdad de la mujer ${ }^{67}$. Y quiénes piensan que es cierto que el lenguaje por sí sólo no puede alcanzar la igualdad de género, pero si no se modifica, se retrasa la igualdad ${ }^{68}$.

a través de la interacción social. D. TANNEN, op. cit., pág. 22. A este respecto, se señala que la interrupción puede ser, (no necesariamente desde luego), una señal de dominación, y la superposición, una forma de colaboración. Naturalmente, la dominación que los hombres ejercen sobre las mujeres a través del lenguaje adquiere diferentes formas en el contexto y en la intención. Es también posible dominar a través del silencio y de la superposición, cuándo el poder ya se tiene y se procura perpetuarlo. La autora crea algún concepto nuevo para clarificar esta situación, como el de superposición cooperativa, en oposición al de interrupción, para aquellos casos en los que ésta es de apoyo y no de obstrucción, pág. 62. En cuánto al estereotipo misógino, considera que aparece porque el uso de la superposición cooperativa tan frecuente en las mujeres, produce un ruido que se ha identificado por los hombres como de gallinas cluecas, pág. 81 .

${ }^{66}$ El lenguaje no es posición disponible de uno u otro de los interlocutores. Toda conversación presupone un lenguaje común o mejor dicho constituye desde si un lenguaje común. GADAMER, Verdad y método, cit., pág. 456.

${ }^{67}$ A. López García y R. Morant, Gramática femenina, Edit. Cátedra. Madrid, 1991, pág. 56 , creen que la discusión acerca del cambio en lenguaje es una cuestión bizantina, y que cuándo cambien las relaciones de las mujeres con la sociedad, cambiará el lenguaje. Igualmente F. MoRENO FERNÁNDEZ, Sociolingüistica en EE.UU., 1975-1985, edit. Agora. Málaga, 1988, quién parte de la idea de que la desigualdad de la mujer se manifiesta en el lenguaje pero no la provoca. De ahí que «se manipulan, cuándo no se desconocen, criterios lingüísticos, para dejar patente la necesidad de un cambio, que en sí mismo, no puede producirse a través del lenguaje. Cuándo las sociedades cambian, las lenguas del mundo lo harán con toda naturalidad», pág. 150-1.

${ }^{68}$ En ¿Cómo comunicarse en el hogar y en el trabajo? E. FELUI ARQUIOLA y otras. En Sexismo en el lenguaje. Servicio de Publicaciones de la Diputación de Málaga, 1999, pág. 196, dónde analizan la posición de varias autoras respecto de la necesidad de integrar los cambios en el lenguaje dentro de las demás medidas de igualdad. 


\section{EL DERECHO}

\section{El lenguaje de género en el derecho}

Las normas jurídicas necesitan una formulación clara y precisa. Es necesario que el lenguaje jurídico exprese con claridad y precisión sus exigencias normativas. Esta necesidad, que es consustancial al derecho en cualquier época de la Historia, lo es más aún en los momentos actuales, en los que el pluralismo ordinamental obliga a la coexistencia de diferentes normas producidas por muy distintos parlamentos. La articulación de los ordenamientos europeo, estatal y autonómico dota de lenguajes muy diferenciados a cada uno de estos conjuntos normativos. La exigencia de seguridad jurídica que debe tener el lenguaje jurídico es especialmente necesaria en un contexto histórico como éste.

Por otra parte, la legitimación del derecho en una sociedad democrática se sostiene, fundamentalmente, en la racionalidad de los procesos de decisión. Esto confiere una importancia esencial a las teorías de la argumentación jurídica del derecho, basadas en el diálogo social y en la idea de que el derecho se desenvuelve en un proceso discursivo, que exige la comprensión y aceptación de las normas jurídicas ${ }^{69}$. Desde esa concepción, el derecho ha evolucionado recientemente a posiciones relacionadas con su legitimación por la vía de la argumentación racional ${ }^{70}$.

Esta concepción del derecho como un proceso de racionalización compartida, exige a su vez la condición de sujeto para integrarse y formar parte del diálogo entre interlocutores sociales ${ }^{71}$. Condición de sujetos que han tenido negada las mujeres hasta momentos muy recientes de la Historia ${ }^{72}$.

${ }^{69}$ Una evolución de las teorías de la argumentación en el derecho, desde su origen en el segunda mitad del siglo XX en F. BALAGUER, Fuentes del Derecho, vol. I. Tecnos. Madrid, 1991, págs. 68-80.

${ }^{70}$ En lo que se refiere al plano constitucional, las exigencias del art. 24 y $120 \mathrm{CE}$ acerca de la motivación de las resoluciones judiciales. La exigencia de una Constitución abierta al pluralismo y a los intérpretes constitucionales, en P. HäBERLE. Cfr. Pluralismo y Constitución. Tecnos. Madrid, 2002.

71 «Il riconoscimiento iniziale della pretesa altrui presuppone quinde un più profondo riconoscimiento dell' altro in quanto altro soggetto del poder pretendere nel medio della parola. Al fondo si delinea el riconoscimiento dell' altro in quanto soggetto che si costituisce nel medio della parola e della incondizionata domanda di senso che la sostiene». P. SAVARESE, La pretesa e la regola. Edit. Giuffrè. Milano, 1999, pág. 73.

${ }^{72}$ Sobre la noción de sujeto constitucional en relación con la posición de debilidad social, C. DE CABO, Teoría constitucional de la solidaridad. Marcial Pons. Madrid, 2006. 
Ahora bien, antes de abordar la exigencia de una técnica legislativa adecuada a la igualdad de género, es necesario analizar cuál es la naturaleza del lenguaje jurídico y su relación con el lenguaje ordinario. Se parte por lo general en la doctrina de una identidad inicial del lenguaje jurídico respecto del lenguaje ordinario, si bien se matizan las peculiaridades que ofrece el lenguaje jurídico en cuánto lenguaje especializado y técnico ${ }^{73}$. El lenguaje legal no es más que una parte del lenguaje natural ${ }^{74}$, y participa por lo tanto de su misma naturaleza ${ }^{75}$. Esta afirmación nos permite considerar el lenguaje en el derecho, sin diferencias metodológicas significativas, respecto de lo que puede entenderse como el lenguaje adecuado de género en una teoría general del lenguaje ${ }^{76}$. La estructura lingüística del derecho difiere del lenguaje común por su exigencia de formalización $^{77}$. El lenguaje común puede ser convencional, impreciso y vago en su significación, pero en el derecho han de precisarse los términos para conseguir el menor margen posible de apertura semántica.

Dicho esto, la introducción del lenguaje de género en el derecho ha de tener en cuenta que el lenguaje legal contiene exigencias ineludibles. Las reivindicaciones feministas han introducido en el derecho el lenguaje de género para hacer visible la realidad de las mujeres en la sociedad política y jurídica. También desde el derecho se reconoce que los cambios políticos, adquieren representaciones simbólicas distintas ${ }^{78}$. Todo cambio político se acompaña de una retórica parti-

${ }^{73}$ En tal sentido se expresa la doctrina actual. Para V. Iturralde, el lenguaje jurídico es «en relación con el lenguaje común, un lenguaje especial; es decir, un lenguaje que, si bien tiene su fundamento en el lenguaje natural, adopta particularidades propias que hacen que podamos referirnos a él como un lenguaje tecnificado». En Sistema legal y lenguaje jurídico. Edit. Tecnos. Madrid, 1989, pág. 24.

74 Austin, Como hacer cosas con palabras. Edit. Paidós, 1990, pág. 39 y ss. Así lo recoge también P.S. Coderch cuando dice que «el lenguaje legal es la parte del lenguaje natural en el que se expresa la legislación de que se trate». P. S. CODERCH, «Elementos para la definición de una técnica legislativa». En GRETEL. CEC. Madrid, 1989, pág. 20.

75 Para Guastini, quién participa de la idea del derecho como discurso, «el derecho no es más que un fenómeno lingüístico». R. GuASTinI, Il diritto come linguaggio. G. Giuppichelli editore. Torino, 2001, pág. 7.

76 J.R. Capella recogiendo aportaciones de Wróblewski y otros autores, distingue entre lenguaje legal y lenguaje de los juristas, reservando la primera expresión para los textos normativos, y la segunda para los operadores jurídicos. En El derecho como lenguaje. Edit. Ariel. Barcelona, 1968, pág. 33.

77 La formalización del lenguaje en el derecho es una exigencia de su propia normatividad. El lenguaje jurídico necesita precisión, tecnificación, y axiomatización. Ib., pág. 245.

${ }^{78}$ E. GARCÍA DE ENTERRÍA, op. cit., pág. 41, en referencia a la Revolución Francesa. En La lengua de los derechos. La formación del Derecho Público europeo tras la Revolución Francesa. Alianza Universidad. Madrid, 1994. 
cular que crea un lenguaje específico, en cuya lógica se cobijan esos cambios. Por tanto, a la urgencia de la modificación del lenguaje en el derecho ha de superponerse, igualmente, su necesaria tecnificación jurídica.

Una vez establecida esa posición, dentro de la estructura misma del derecho, y en el proceso de creación de las normas jurídicas, se impone la reflexión sobre la exigencia de integrar el lenguaje de género, como un elemento más de corrección técnica en la creación de las normas. Pese a que desde algunos sectores doctrinales se ha discutido la pertinencia de integrar la posición de género en los textos legales, y no se puede negar desde luego, que estamos en un momento inicial de estas formulaciones, lo cierto es que la irrupción de la mujer en el ámbito público exigen que el lenguaje designe correctamente los contenidos adecuados a la norma, y por lo tanto, se corresponda formalmente a los significados que designa. Desde este punto de vista, lo que para estos sectores doctrinales aparece como una irregularidad o deficiencia en la técnica jurídica, constituye para otro sector la mayor exigencia de perfeccionamiento en el proceso de realización de las normas jurídicas ${ }^{79}$.

Tampoco se ha estudiado todavía la relación entre poder y lenguaje ${ }^{80}$. El hecho de que el lenguaje tenga una función reproductora, en cuanto que ideoló-

79 Ciertamente esta exigencia de adecuación del lenguaje al género en el derecho no es ajena al incremento de la presencia de la mujer en la política. En este sentido, un cambio político, en palabras de García de Enterría referidas a la Revolución Francesa, implica un cambio léxico. E. GARCÍA DE ENTERRÍA, op. cit., pág. 26.

${ }^{80}$ Hablamos de lenguaje de género. Sí es abundante la doctrina y la jurisprudencia en relación a lo que se ha denominado la «realidad plurilingüe» en nuestro ordenamiento. La regulación del art. 3.1 y $2 \mathrm{CE}$ en cuánto al reconocimiento del derecho a las lenguas, ha generado una importante jurisprudencia del TC sobre el estatuto de la cooficialidad lingüística. Las SSTC 82, 83, 871 88/1983, 137/1986, 74/1987, 123/1988, 195/1989, 19/1990, 46/1991, y 337/1994, entre otras, que resuelven acerca de la constitucionalidad de las diferentes leyes autonómicas sobre el uso del euskera, catalán, valenciano o gallego. En ellas se recogen aspectos fundamentales de la lengua en relación con los valores culturales, la necesidad de protección de las diferentes lenguas y los límites constitucionales de su uso, así como las limitaciones del art. 149.1.1 y los diferentes títulos competenciales concernidos en su regulación. En la STC 337/1994, afirma el TC que la lengua es el vehículo de la personalidad, constituye el medio para el ejercicio de la facultad más propia del ser humano, y es instrumento para la actuación de una buena parte de los derechos humanos y de las libertades públicas, lo que justifica el derecho de los padres a exigir el idioma en el que prefiere que sean educados sus hijos. En cuanto a la doctrina, en J. Vernet, coord. "Dret lingüístic». Universitat Rovira i Virgili. Barcelona, 2003, recoge y analiza la normativa internacional y comunitaria, de los derechos lingüísticos, con comentarios sobre la jurisprudencia del TC en la materia. Igualmente en n. 2 de la revista "Teoría y realidad constitucional», segundo semestre, 1998, dedicado a la Constitución y la lengua. Un análisis de la jurisprudencia del TC sobre los derechos lingüísticos, en J. A. MONTILLA, «Lenguas minoritarias y normalización lingüística ante el Tribu- 
gicamente puede crear las condiciones materiales sobre la posición que ocupen socialmente mujeres y hombres, nos permite entender como el lenguaje se desarrolla y se dota de funciones para la perpetuación de un modelo de dominación $^{81}$. Así, es a través del lenguaje como se puede sostener ideológicamente esa dominación. De ahí la necesidad de utilizar la perspectiva de género en el lenguaje, como una de las maneras de eliminar esa dominación. Y esto, no solamente desde el cambio de uso del masculino genérico por un lenguaje neutro, sino desde un estudio más amplio del lenguaje como instrumento de dominación del patriarcado.

\section{La técnica legislativa y el lenguaje de género}

La posibilidad de elaborar un lenguaje comprensivo de las diferencias de género en el derecho deriva de las propias exigencias de una técnica jurídica correcta. En este sentido, el lenguaje de género participaría también de las exigencias de la técnica legislativa general. Exigencias que, ciertamente, no presentan en nuestro ordenamiento un alto grado de desarrollo ni formalización ${ }^{82}$. Hay además circunstancias relacionadas con el desarrollo del Estado Social y el pluralismo político que dificultan una mayor exactitud del contenido de las leyes ${ }^{83}$. Ni siquiera es objeto específico de los estudios de derecho la téc-

nal Constitucional». En Revista de la Facultad de derecho de la Universidad de Granada. N. 5, 2002, págs. 335-348.

81 D. Tannen ha señalado como hay quienes creen erróneamente que abordar como diferencias culturales las diferencias de género en los modos de hablar, implica que los hombres no dominan a las mujeres, sino que únicamente no las comprenden. Muy al contrario, señala la autora, que en el lenguaje, las diferencias de estilo operan en detrimento de los miembros de grupos estigmatizados y a favor de quienes tienen el poder para imponer sus interpretaciones. TANNEN, D., Genero y discurso, Edit. Paidos. Barcelona, 1996, pág. 19-20.

82 Más aún si tenemos en cuenta, como señala P. Salvador Coderch, que el técnico en legislación asume el primado de la política, dadas las limitaciones textuales que generalmente exige el consenso legislativo mediatizado por el pluralismo político. Las mejores soluciones técnicas no suelen ser posibles por las limitaciones y urgencias políticas. GRETEL, op. cit., pág. 15.

83 J. Cano ha llamado la atención acerca de la relación entre el Estado Social y estas dificultades en «Insuficiencias del procedimiento legislativo en el Estado Social». En «El constitucionalismo en la crisis del estado Social». Servicio de Ediciones de la Universidad del País Vasco, Bilbao, 1997, pág. 647 y ss. también en general cobre la técnica legislativa en nuestro ordenamiento. M.J. MONITOR CHINER, Adecuación al ordenamiento y factibilidad: Presupuestos de calidad de las leyes. CEC. Madrid, 1989. M.L. BALAGUer CALLEJÓN, El Recurso de inconstitucionalidad. CEPC. Madrid, 2001, págs. 122 a 134. M.L. BALAGUER CALLEJÓN, Interpretación de la Constitución y orde- 
nica legislativa como tal, y la regulación jurídica de las exigencias técnicas de las leyes es muy escasa ${ }^{84}$.

El esfuerzo que en este sentido ha de hacerse no se le oculta a nadie. Más aún si desde los sectores especializados en el lenguaje, destacadamente desde la Real Academia de la Lengua Española, no se colabora siquiera con una posición favorable. Pero estas dificultades no obvian la necesidad de encontrar la posibilidad de establecer criterios, principios y medidas que coadyuven a la solución de los problemas técnicos. El encuentro entre lingüistas y juristas no siempre ha sido posible, y esa distancia interviene también como un factor obstativo importante para elaborar un lenguaje jurídico adecuado al género. Los lingüistas a menudo consideran que los juristas oscurecen el lenguaje ${ }^{85}$.

Después de la normativa estatal y autonómica existente ya en numerosas CC.AA. acerca de la necesidad de la evaluación del impacto de género en las normas jurídicas, no puede mantenerse un proceso de elaboración de las normas que ignore la dimensión lingüística. Más aún, la primera exigencia del impacto de género en las normas jurídicas la constituye el lenguaje, entendido como simple corrección gramatical de la norma.

Desde las autoridades lingüísticas ha habido una fuerte resistencia a admitir estas iniciativas, que se han considerado gramaticalmente incorrectas. La Real Academia de la Lengua Española ha cuestionado el propio término "género» como incorrecto, inexacto e inconveniente. La RAE considera en relación con el género que «las palabras tienen género mientras los seres vivos tienen sexo». Entiende que el término género es una traducción de la palabra anglosajona "gender», que en los años setenta con el auge de los estudios feministas se ha extendido a otras lenguas. Este término ha servido para diferenciar la categoría biológica de la categoría socio-cultural que implican las diferencias de orden social $^{86}$. Dentro del ámbito sociológico puede resultar útil e incluso necesaria, pero

namiento jurídico. Tecnos. Madrid, 1997, pág. 93 y ss. M. GASCÓn ABELLÁn, «Calidad de las leyes y técnica legislativa». Revista Española de la función consultiva. Valencia, pág. 41 y ss.

${ }^{84}$ Hasta la década de los setenta no se inician en Europa los estudios sobre técnica legislativa. GRETEL, op. cit., pág. 37. Por otra parte, aún no hay trabajos sistematizados sobre técnica legislativa, sino meras aproximaciones a una teoría de la legislación.

${ }^{85}$ Sobre la falta de claridad en el lenguaje jurídico, LÁZARO CARRETER, El nuevo dardo en la palabra. Edit. Alianza, Madrid, 2005, pág. 170.

${ }^{86}$ Con ocasión de la tramitación del Proyecto de Ley Orgánica de la 1/2004, de 28 de diciembre, de erradicación de la violencia de género, la RAE de «motu proprio» envió un Informe al Gobierno aprobado en sesión plenaria académica de 13 de mayo de 2004, por el que instaba al Gobierno a cambiar el nombre de la ley. En este Informe la Academia llama la atención al Gobierno acerca de la necesidad de cambiar esta expresión, de origen anglosajón, difundida a raíz del 
para la Academia no es posible como sinónimo de sexo. Para las expresiones como discriminación de género y otras debe decirse «sexo" y no "género». El uso del masculino en referencia a ambos sexos designa para la RAE a todos los individuos de la especie, sin distinción de sexo. A pesar de ello, dice, en los últimos tiempos, por razones de corrección lingüística, se está extendiendo la costumbre de hacer explícita en estos casos la alusión a ambos sexos. Se olvida que en la lengua está prevista la posibilidad de referirse a colectivos mixtos a través del género gramatical masculino, posibilidad en la que no debe verse intención discriminatoria alguna, sino la aplicación de la ley lingüística de la economía expresiva. Considera el lenguaje dual como una engorrosa repetición, y la arroba como un signo no lingüístico. Por tanto, la RAE no reconoce necesidad alguna de avanzar en la comprensión y entendimiento de un lenguaje de género. Alguna posición particular ha aceptado sin embargo el término sin reservas ${ }^{87}$. Tampoco ha considerado correcta la utilización del lenguaje de género ${ }^{88}$.

Una parte de la doctrina lingüística también se ha posicionado claramente en contra de la implantación del lenguaje de género, desde la misma terminología ${ }^{89}$

Congreso sobre la Mujer celebrado en Pekín en 1995. En español la palabra género atiende más bien a un criterio clasificatorio. Hay otras expresiones a juicio de la Academia que responden mejor a la denominación de la ley. Para demostrarlo, recoge de Internet las diferentes denominaciones y constata que la de "violencia doméstica» es la más utilizada y es la que aconseja. Como bien recoge el Informe de la Academia, el término "género" ya se encontraba recogido en las leyes 50/1997 y 30/2003, en las que se había regulado justamente el impacto por razón de género.

${ }^{87}$ García Meseguer justifica plenamente esta diferenciación, op. cit., pág. 82.

${ }^{88}$ El informe emitido a solicitud del Parlamento de Andalucía de febrero de 2006, contiene la mejor doctrina en esta materia. Bien es cierto que la pregunta ya venía solicitada con torpeza, porque solamente preguntaba por la corrección de los desdoblamientos en el lenguaje. La respuesta participa de esa torpeza asumiendo ese reduccionismo. Para la Real Academia, «El empeño de realizar sistemáticamente estos desdoblamientos tiene su origen en unos casos en el desconocimiento de que gramaticalmente se define como uso genérico del masculino gramatical en su caso, en la voluntad declarada de alguno por parte de determinados colectivos sociales y políticos de suprimir este rasgo inherente al sistema de la lengua como si fuese consecuencia mas de la dominación histórica del varón sobre la mujer en las sociedad patriarcales. Sin embargo el uso genérico del masculino gramatical tiene que ver simplemente con el principio básico de la economía lingüística que supone la materialización en el ámbito comunicativo de la tendencia del ser humano a obtener sus fines con el menor esfuerzo posible».

89 Sobre el termino «violencia de género»: hiere el sentimiento lingüístico castellano porque confunde genero con sexo, e idea otro nombre, el de violencia de superioridad, porque deriva del poder. Sobre ella vuelve en la pág. 221, notoriamente contrariado porque a su juicio se ha utilizado en los documentos oficiales una influencia del inglés. En inglés las palabras carecen de género, gramatical. En España las palabras tienen género, pero las personas no tienen género sino sexo, aquellas pueden ser masculino y femenino, pero estas solo pueden ser varones o hembras. Ante ese en- 
hasta las fórmulas concretas, como el dualismo ${ }^{90}$ o la arroba cibernéti$\mathrm{Ca}^{91}$.

Esta posición se superpone en el tiempo con algunas propuestas que, tanto desde el feminismo como desde una incipiente regulación normativa, están introduciendo la sustitución del masculino genérico, por el dualismo, el «se» impersonal seguido de la expresión verbal, y el uso de expresiones neutras.

En el orden de propuestas concretas que se formulan para la erradicación del uso sexista del lenguaje, se está todavía en un proceso de indagación acerca de las cuestiones básicas del lenguaje binario, y no hay siquiera un primer intento de sistematización del lenguaje de género en el lenguaje ordinario, lo que hace aún más difícil su formulación en el derecho. Hay quién considera que el término «hombre» debe sustituirse por persona, pero también hay lecturas de «hombre» como genérico de la especie humana y no como opuesto a mujer, (en realidad el opuesto a mujer es varón). Y se propone su uso para abarcar a ambos géneros ${ }^{92}$. De ese modo la mujer no habrá renunciado a un término que la comprende también a ella y que el androcentrismo había derivado al varón ${ }^{93}$.

Otras veces se realizan intentos de uso del lenguaje por parte del feminismo que tienen un contenido meramente reivindicativo pero que no parecen técnicamente muy adecuados para implantarse en la comunidad lingüística, pues para que un neologismo sea acogido socialmente, ha de satisfacer unas mínimas exigencias $^{94}$. También es aprovechable el masculino asimétrico ${ }^{95}$, aunque a la RAE

treguismo lingüístico, se muestra disgustado, «y de tales y de otras reuniones internacionales, el término se ha expandido como un infundio. Lo señalé hace meses, pero por ahí tenemos galopando tan aberrante galicismo; y, a quienes tan justa y briosamente combaten la violencia contra el sexo, ejerciéndola cada vez más contra el idioma.». F. LÁZARO CARRETER, El dardo y la palabra, op. cit., pág. 135.

${ }^{90} \mathrm{El}$ autor se manifiesta claramente contrario al lenguaje de género, y confunde, como tantas otras personas, éste con el dualismo lingüístico de los pares ciudadanos-as, aunque existan ocasiones que lo requieren o lo aconsejan, ralentiza el discurso y produce tedio, op. cit., pág. 72.

91 En contra de la arroba cibernética. Ib., pág. 112.

92 García Meseguer, aconseja que se use el término «hombre» como genérico para que se vaya abriendo cada vez mas paso la idea de que hombre engloba a la humanidad. Y deja la denominación de varón para el opuesto al de mujer, op. cit., pág. 47.

${ }_{93}$ García Meseguer considera que esto enriquecerá el lenguaje con aportaciones novedosas, y que en tal sentido la lingüística tiene mucho que agradecer al feminismo. Ib., pág. 173.

${ }^{94}$ García Meseguer contempla tres posibilidades de neologismos: feminizar el termino, extenderlo a la mujer con artículo en femenino, y utilizarlo sin modificación alguna. Ib., pág. 120.

95 Sobre como el masculino asimétrico siempre tendrá un doble valor semántica, en cuanto engloba y va solo el femenino solo un valor. Esto obliga a la mujer a un proceso diferencial de aprendizaje. Debe analizar si cada masculino la engloba o es específico. Ib., pág. 159. 
esto le parecen artificios en el mejor de los casos innecesarios y en el peor, rebuscados y hasta ridículos.

En línea de propuestas, y dado el escaso nivel de sistematización actual del lenguaje de género, conviene no renunciar totalmente al masculino genérico ${ }^{96}$, o usar el término genérico de hombre con la intención de que se implante para uso de los dos géneros, así como tener cierta cautela con la feminización de ciertos términos que exageran ese tono reivindicativo de la igualdad ${ }^{97}$. También pueden utilizarse determinadas figuras gramaticales que facilitan la neutralidad ${ }^{98}$. Y una cierta prudencia en el uso de esas duplicidades, cuyo abuso puede resultar irritante.

\section{La posibilidad de una ley de técnica legislativa, que integre el lenguaje de género}

La implantación del lenguaje de género en el derecho va ligada necesariamente a la exigencia de una técnica legislativa adecuada. Sobre esa exigencia de legislar bien se ha pronunciado con mucha frecuencia la Unión Europea99.

En este sentido, la calidad del producto legislativo, ha sido una preocupación tanto del Parlamento de Europa como de la Comisión y del Consejo. El Libro Blanco sobre la gobernanza europea que la Comisión presenta en julio de 2001 incide en la buena legislación como condición ética de buen gobierno. También

96 Para avanzar en la igualdad, al feminismo le interesa fomentar el masculino específico. García Meseguer, op. cit., pág. 161.

${ }^{97}$ García Meseguer distingue entre juegos feministas del lenguaje como reivindicativos, y verdaderas propuestas. Ib., pág. 74.

98 Pertinencia de la utilización de figuras poéticas en las ciencias jurídicas, tales como: la metáfora que es el desplazamiento de significado a causa de una relación de analogía, o la sinécdoque, tropo que consiste en la utilización de un término más restringido o amplio. La metonimia, que es la sustitución de un término por otro que está en relación con él. Y finalmente la elipsis, que suprime un elemento de la oración que se sobreentiende intelectualmente. Una relación de las figuras poéticas en E. TORRE y M. A. VÁZQUEZ Fundamentos de poética española. Edit. Alfar. Sevilla, 1986.

99 También la doctrina. Sobre la necesidad de construir un lenguaje europeo en la Unión Europea, F. BALAGUER CALLEJÓN, «La construcción del lenguaje jurídico en la Unión Europea», en Revista de Derecho Constitucional Europeo, n. 1. Instituto Andaluz de la Administración Pública. Sevilla, 2004. Para el autor, es el momento de articular un lenguaje adecuado de género. «En la Unión Europea la promoción de la igualdad de género en el lenguaje debe pasar también al primer plano de la construcción constitucional y jurídica de la Unión. Como en otros tantos aspectos, la Unión podrá servir de modelo para sistemas jurídicos menos evolucionados ayudando así a su progreso constitucional», pág. 310 . 
el Consejo de la Unión Europea aprueba en 2003 un proyecto de acuerdo interinstitucional sobre la forma de legislar mejor, no solamente las instituciones específicamente europeas, sino también ayudando a los Estados a crear homogeneidad y uniformidad en los procesos legislativos.

En lo que se refiere específicamente al lenguaje de género, la Recomendación n. 90 (4) del Consejo de Europa, adoptada por el Consejo de Ministros de 21 de febrero de 1990, para la eliminación del sexismo en el lenguaje, ha contribuido a la elaboración de una normativa en nuestro ordenamiento jurídico estatal y autonómico, de adecuación a esa exigencia europea ${ }^{100}$.

100 Este desarrollo ha sido muy desigual en los diferentes ordenamientos. Algunas instituciones han optado ya por un lenguaje de género. La Organización Mundial de la Salud, en su grupo intergubernamental, encargado de examinar los métodos de trabajo del consejo ejecutivo, aconseja la utilización del lenguaje neutral en su reglamento de régimen interior. La conferencia de la FAO aprobó en Resolución 7/99, la utilización del lenguaje neutral en sus textos. La UNESCO, la UIT y otros tantos organismos internacionales han hecho lo propio. En los ordenamientos autonómicos, es en Andalucía donde ha adquirido un mayor desarrollo hasta ahora, el lenguaje jurídico de género. Se inicia con la aprobación de la Orden de 24 de noviembre de 1992, conjunta de la Consejería de Gobernación y la Consejería de Asuntos Sociales, sobre la eliminación del lenguaje sexista en los textos y documentos administrativos, (BOJA n. 126 de 5 de diciembre de 1992), que exige que en los textos y disposiciones administrativas no se contenga discriminación alguna por motivo de sexo. A tal fin se crea una Comisión paritaria entre la Consejería de Gobernación y el Instituto Andaluz de la Mujer, al objeto de progresar en el análisis del lenguaje no sexista. Después se produce una Instrucción de 16 de marzo de 2005 de la Comisión General de Viceconsejeros, para evitar el uso sexista del lenguaje en todas las disposiciones de carácter general de la Junta de Andalucía, que establece tres reglas esenciales para homologar los textos legales: la regla de inversión, consistente en sustituir la palabra dudosa por la correspondiente de género opuesto, de tal modo que si la frase resulta así inadecuada, debe cambiarse la palabra. La regla de evitación del masculino genérico, mediante la utilización de términos genéricos, perífrasis, infinitivos, pronombres neutros, metonimias, aposiciones y construcciones gramaticales que faciliten la neutralidad de género. Y la regla específica de la Administración, que exige la citación del género en el cargo que en ese momento desempeñe la persona. Recomienda la evitación de barras y arrobas, y en la medida de lo posible la duplicación terminológica. Esta última medida responde además a las exigencias del art. 139 de la Ley 18/2003, de 29 de diciembre, por la que se aprueban las medidas fiscales y administrativas, de la Comunidad Autónoma de Andalucía. Este precepto exige que «todos los proyectos de ley y reglamentos que apruebe el Consejo de Gobierno deberán tener en cuenta de forma efectiva el objetivo de igualdad por razón del género». En desarrollo de este precepto, el Decreto 93/2004, de 9 de marzo, regula el informe de evaluación del impacto de género en los proyectos de ley y reglamentos que apruebe el Consejo de Gobierno, y establece el procedimiento y los criterios para llevara a efecto esa evaluación. Recientemente se ha reformado el Reglamento del Parlamento de Andalucía, (Resolución de 22 de noviembre de 2007, de la Presidencia del Parlamento de Andalucía, por la que se da publicidad a la Reforma del Reglamento del Parlamento de Andalucía. BOJA n. 11 de diciembre de 2007). Esta reforma se efectúa conforme a unos criterios aprobados por el Acuerdo de la Mesa del Par- 
En nuestro ordenamiento jurídico hay algunas normas que regulan la implantación de un lenguaje de género en el derecho.

Estas normas en la actualidad se limitan al Acuerdo del Consejo de Ministros, de 22 de julio de 2005, que ha sustituido a la Resolución, de 15 de noviembre de 1991, de la Subsecretaría del Ministerio de Relaciones con las Cortes y de la Secretaría de Gobierno. Esta Resolución publicada en el BOE de 29 de julio de 2005, contiene un Anexo en el que se publica el Acuerdo por el que se aprueban las directrices de técnica normativa. Sustituye al Acuerdo de 18 de octubre de 1991, que se limitaba a los Anteproyectos de ley, y ahora se extiende a los de los decretos leyes y decretos legislativos, si bien por analogía estas disposiciones normativas venían haciendo uso del Acuerdo. En lo que ahora interesa, el Acuerdo de 2005 contiene unas directrices en el punto IV que se refieren específicamente a los criterios lingüísticos generales. Se exige: lenguaje claro y preciso, de nivel culto, pero accesible ${ }^{101}$.

Por otra parte, el Tribunal Constitucional ha delimitado con cierta exactitud entre la defectuosa técnica legislativa y la inconstitucionalidad, de manera que una técnica legislativa defectuosa no acarrea la nulidad del precepto ${ }^{102}$.

Si esa normativa de impacto no había sido regulada en algunas CC.AA., la reciente $\mathrm{LO} 3 / 2007$, de 22 de marzo, ha establecido de manera imperativa, para

lamento de Andalucía 7-05/AEA-000112, de 16 de noviembre de 2005, (BOPA n. 337, de 12 de diciembre), y cuyas recomendaciones son: la limitación de los desdobles, y en el caso de usarse se utilizará primero el masculino, y el plural en masculino genérico, la perífrasis, los genéricos, la metonimia, los pronombres sin marca de género, la omisión del sujeto, y algunos otros recursos, nunca la arroba cibernética ni las barras, salvo, estas últimas, en uso de formularios. El resultado de la utilización de estos criterios no ha sido demasiado satisfactorio desde el punto de vista técnico, pero supone una decisión política muy importante para avanzar en el lenguaje de género.

101 Se dice que el destinatario de las normas jurídicas es el ciudadano. Por ello el lenguaje ha de ser accesible al ciudadano medio, de manera clara, precisa y sencilla. Se debe evitar el uso de extranjerismos, las construcciones lingüísticas inusuales, los epítetos, las perífrasis, las oraciones pasivas, o la pobreza de las expresiones. Y sobre todo, debe adecuarse la norma jurídica a las normas lingüísticas generales de la Real Academia Española, de manera que la redacción de los textos seguirá sus normas ortográficas y gramaticales, y su Diccionario. Las dudas que se presenten se solventarán de acuerdo con el Diccionario Panhispánico de dudas. La Subsecretaria de la Presidencia, en colaboración con la Real Academia Española, elaborará unas instrucciones complementarias de tipo práctico que ayuden a aplicar los criterios lingüísticos generales en disposiciones y normas oficiales. Dichas instrucciones formarán parte integrante de estas directrices.

102 A este respecto el TC ha distinguido claramente entre juicio de constitucionalidad y de perfectibilidad, correspondiendo su pronunciamiento claramente al primer supuesto, y no siendo pertinente en el segundo. SSTC 11/1983, 49/1988, 76/1990, 222/1993, 341/1993, 68/1996, $139 / 2005$. 
la totalidad del ordenamiento jurídico, la exigencia del lenguaje de género. A partir del art. 14. Pf. 11) de la ley puede decirse que toda norma que no contenga la exigencia del lenguaje de género de manera correcta, adolece de una defectuosa técnica legislativa. La ley, consciente de esta realidad, pretende introducir el lenguaje de género, fundamentalmente en la Administración Pública y en los medios de comunicación ${ }^{103}$. Y regula con un carácter bastante general la recomendación de que no se haga un uso sexista del lenguaje ${ }^{104}$. Con esta regulación, la ley se enfrenta a sectores amplios de la sociedad que considera correcto el uso del masculino genérico para designar tanto a las mujeres como a los hombres ${ }^{105}$.

La exigencia de una evaluación del impacto de género en las leyes proporciona una cobertura teórica suficiente para cumplimentar el lenguaje de género. Sin embargo, es difícil con esa sola exigencia la solución a la técnica legislativa que exigiría la utilizaron del lenguaje de género en las leyes, habida cuenta la parquedad con que se ha regulado la evaluación del impacto de genero ${ }^{106}$. Hubiera sido deseable que el concepto de impacto de género se hubiera desarrollado más en las normas que lo regulan. Esta previsión de desarrollo se encuentra en el art. 18 que establece la necesidad de determinar reglamentariamente los términos de elaboración de un informe periódico del impacto de género ${ }^{107}$.

${ }^{103}$ El pf. 11 del art. 14 donde se establecen los criterios generales de actuación de los poderes públicos, está el de «la implantación de un lenguaje no sexista en el ámbito administrativo y su fomento en la totalidad de las relaciones sociales, culturales y artísticas».

${ }^{104}$ En el art. 37 cuándo se habla de la Corporación de RTVE en el ejercicio de su función de servicio público, se dice que perseguirá los siguientes objetivos: b) utilizar el lenguaje en forma no sexista. El art. 38 al regular las funciones de la agencia EFE dice que velará por el respeto del principio de igualdad entre mujeres y hombres «y, en especial, por la utilización no sexista del lenguaje», y perseguirá en su actuación los siguientes objetivos: b) utilizar el lenguaje en forma no sexista. En la misma página, en el art. 45 de la ley, se habla de «trabajadores», en el pf. 1 y en el pf. 4 «trabajadores y trabajadoras».

105 El Dictamen del Consejo de Estado 803/2006, sobre el Anteproyecto de la Ley de Igualdad de Oportunidades entre mujeres y hombres, de 22 de junio de 2006, dirá que «Un ejemplo de estas medidas positivas luce en la propia ley que, desde el mismo título, se aparta del uso generalizado y gramaticalmente correcto del masculino plural inclusivo, para designar ambos sexos e incluso antepone el femenino al masculino «ciudadanas y ciudadanos», "empleadas y empleados».

106 Acerca del contenido material de los informes de impacto, y sus dificultades, F. RUBIO LLORENTE, «El papel del Consejo de Estado en el control de calidad técnica de las normas». En Revista Española de la Función Consultiva, julio-diciembre, 2006, págs. 31 a 32. El Presidente el Consejo de Estado recomienda esfuerzos complementarios de formación, información, y sensibilización por parte de las Unidades Administrativas y órganos encargados de realizar ese trabajo.

107 El RD 1729/2007, de 21 de diciembre, regula la elaboración del Informe periódico, relativo a la efectividad del principio de igualdad entre mujeres y hombres. Es también una regula- 
La exigencia de una normativa que regule la calidad técnica de las normas plantea a su vez problemas complejos, ahora ya desde las exigencias competenciales de un Estado compuesto. La posibilidad de regulación estatal de unas bases mínimas, a las que deban ajustarse los Parlamentos autonómicos, no está exenta de algunas dificultades técnicas. El uso reciente por parte del Estado del art. 149.1.1 para regular algunas materias competencialmente atribuidas a las CC.AA. como la asistencia social, ha sido objeto de recurso de inconstitucionalidad por alguna Comunidad Autónoma ${ }^{108}$. La colisión competencial entre el Estado y las CC.AA. en orden a la técnica legislativa puede obstaculizar una ley estatal.

En cualquier caso, bien regulando el Estado las bases de una técnica legislativa para la elaboración de las normas, o mediante una ley de aplicación exclusivamente estatal, las consecuencias no serían demasiado distintas, por el más que probable efecto mimético que se viene mostrando en la regulación de materias similares. En la legislación acerca de la paridad de género, la iniciativa de algunas CC.AA. fue muy pronto asumida por las demás Comunidades y por el propio Estado. Por ello, la cuestión competencial no debe plantearse como un obstáculo determinante de la legislación sobre la calidad técnica de las leyes.

También sería deseable que por parte de los organismos que tratan la calidad técnica de las leyes, muy destacadamente los Gabinetes Jurídicos, Cuerpos Le-

ción muy sucinta, que se limita en sus seis artículos, a establecer el procedimiento por el que la Secretaría de Igualdad elevará al Consejo de Ministros este informe, la recepción de información de los diferentes departamentos ministeriales y su remisión a la Secretaría General de Políticas de Igualdad, y finalmente, su periodicidad bianual. No se determina nada acerca de los contenidos de un informe de evaluación del impacto de género, lo que tiene como consecuencia, además de ese contenido exiguo, la dispersión y asistematicidad de estos contenidos.

108 El Estado ha hecho uso de ese título horizontal con ocasión de la ley 39/2006, de 14 de diciembre, de Promoción de la Autonomía Personal y Atención a las personas en situación de dependencia. La Exposición de Motivos de la ley señala que «la competencia exclusiva del Estado para la regulación de las condiciones básicas que garanticen la igualdad de todos los españoles en el ejercicio de los derechos y en el cumplimiento de los deberes constitucionales, (artículo 149.1.1 $\mathrm{CE}$ ), justifica la regulación, por parte de esta ley, de las condiciones básicas de promoción de la autonomía personal y de la atención a las personas en situación de dependencia mediante la creación de un Sistema para la Autonomía y Atención a la Dependencia con la colaboración y participación de todas las Administraciones Públicas, y con pleno respeto a las competencias que las mismas hayan asumido en materia de asistencia social en desarrollo del artículo 148.1.20 de la Constitución.» La Comunidad Autónoma de Cataluña ha recurrido de inconstitucionalidad esta ley, que está ahora pendiente de sentencia. También la LO 3/2007, de Igualdad de Oportunidades entre mujeres y hombres, apela al art. 149.1.1 para regular básicamente algunas materias competencialmente atribuidas a las CC.AA. 
trados y Consejos Consultivos, se tuviera en cuenta la necesidad de adecuar el lenguaje al género. Hasta ahora sin embargo, el único Consejo Consultivo que lleva a cabo este trabajo es el de Andalucía ${ }^{109}$.

\section{Conclusiones}

PRIMERA. El lenguaje es el elemento que diferencia a la Humanidad del resto de los seres vivos. La importancia del lenguaje estriba en la posición que ocupa en la formación del pensamiento.

SEGUNDA. De ahí la importancia del lenguaje como elemento identitario en las personas y los grupos. Un lenguaje que no responde a la identidad de las personas y cosas, no designa la realidad.

TERCERA. La ocultación de las mujeres por parte del lenguaje es una consecuencia directa del ejercicio del poder por parte de los hombres para mantener la estructura social del patriarcado.

CUARTA. En el estado actual del desarrollo de las ciencias jurídicas se impone el reconocimiento del derecho a ser nombradas las mujeres y a una designación propia, como condición imprescindible del derecho a una igualdad real. El mantenimiento del masculino genérico en el lenguaje no responde a la totalidad de la Humanidad, sino a la designación del hombre.

QUINTA. Es exigencia de una técnica jurídica adecuada el establecimiento de un lenguaje comprensivo de la mujer y del hombre, que recoja la realidad

109 Con carácter general, en todas las disposiciones que le son sometidas a Dictamen. Y de forma especial, insistió el Consejo con ocasión del Proyecto de Reforma del Estatuto de Autonomía de Andalucía. En el punto primero del dictamen se contiene una Observación general que es la contestación a otra en la que la Ponencia advertía que por falta de tiempo no había podido procederse a la corrección del lenguaje en términos de género. El Consejo dice que «no solo comparte positivamente la intención anunciada por la Ponencia de Reforma del Estatuto de realizar una revisión del texto desde el punto de vista del uso no sexista del lenguaje, sino que considera este aspecto de gran importancia. En este sentido basta recordar la doctrina de este Consejo (por todos, dictamen 49/2006 al señalar que "la incorporación de la mujer a la sociedad como sujeto de derechos civiles y políticos, exige la reconsideración del Derecho en términos de igualdad. Uno de los elementos más importantes para conseguir esa igualdad, lo constituye la posibilidad de que las mujeres sean nombradas por el Derecho en su propia identidad de género, y por la extensión del genérico masculino. El lenguaje puede constituir en sí mismo un factor de discriminación por razón del género, si no se denomina por igual a las mujeres y a los hombres, y en ese sentido, el Derecho en su contenido de justicia material exige también la utilización de términos que abarquen por igual a ambos géneros"». 
de las personas que se dedican a la actividad pública, así como que designe a las mujeres como sujetos de derechos y obligaciones jurídicas.

SEXTA. Tal construcción presenta importantes dificultades que deben solventarse científicamente, pero que no deben ser obstructivas del desarrollo adecuado del lenguaje.

SEPTIMA. Coincidente con la necesidad de sistematizar y legislar sobre una técnica legislativa correcta, debe integrarse en esa regulación vía ley estatal, con amparo en el art. 149.1.1 CE, la necesidad de que las normas jurídicas sean adecuadas al impacto por razón de género. Una ley de técnica legislativa, que desde el Estado, establezca las bases mínimas para la producción normativa, sin duda contribuirá a avanzar en el lenguaje igualitario.

\section{Bibliografia}

ARendt, H., La vida del espiritu. Edit. Paidós. Barcelona, 2002.

Austin, J. L., Cómo hacer cosas con palabras. Edit. Paidós. Barcelona, 1990.

Balaguer Callejón, F., Fuentes del Derecho, vol. I. Tecnos. Madrid, 1991.

—, «La construcción del lenguaje jurídico en la Unión Europea», en Revista de Derecho

Constitucional Europeo, n. 1. Instituto Andaluz de la Administración Pública. SEVILLA. 2004.

Balaguer Callejon, M. L., Mujer y Constitución. Edit. Cátedra. Madrid, 2005.

—, Interpretación de la Constitución y ordenamiento jurídico. Edit. Tecnos. Madrid, 1997.

—, El recurso de inconstitucionalidad. CEPC. Madrid, 2001.

Buxo, M. J., Antropología de la mujer. Edit. Anthropos. Barcelona, 1988.

CABo, C de., Teoría constitucional de la solidaridad. Marcial Pons. Madrid, 2006.

CANO BUESO, J., «Insuficiencias del procedimiento legislativo en el Estado Social». En El constitucionalismo en la crisis del estado Social. Servicio de Ediciones de la Universidad del País Vasco, Bilbao, 1997.

CAPella, J. R., El derecho como lenguaje. Edit. Ariel. Barcelona, 1968.

CODERCH, P. S., «Elementos para la definición de una técnica legislativa». En GRETEL. CEC. Madrid, 1989, pág. 20.

Chомsкy, N., Sobre la democracia y educación. Edit. Paidós. Barcelona, 2005.

—, La arquitectura del lenguaje. Edit. Kairos. Barcelona, 2003.

GARCÍA MeSEGUER, A., ¿Es sexista la lengua española? Una investigación sobre el género gramatical. Edit. Paidós. Barcelona, 1994.

Gadamer, H. G., Estética y hermenéutica. Edit. Tecnos. Madrid, 1996.

—, Verdad y método. Edit. Paidós. Barcelona.

—, El giro hermenéutico. Edit. Cátedra. Grupo Anaya. Madrid, 2005.

García de Enterría, E., La lengua de los derechos. La formación del Derecho Público europeo tras la Revolución Francesa. Alianza Universidad. Madrid, 1994. 
Gascón Abellán, M., "Calidad de las leyes y técnica legislativa». Revista Española de la Función Consultiva. Valencia, 2007.

Goddard, A, y Patterson, L. M., Lenguaje y género. Ediciones de la Universidad de Castilla-La Mancha. Cuenca, 2005.

Grupo de Estudios de TÉCNiCA Legislativa, (GRETEL)., Curso de técnica legislativa. CEC. Madrid, 1989.

Guastini, R., Il diritto come linguaggio. G. Guppichelli editore. Torino, 2001.

Habermas, J., Verdad y justificación. Edit. Trotta. Madrid, 2002.

—, La ética del discurso y la cuestión de la verdad. Edit. Paidós. Barcelona, 2003.

HäBerle, P., Pluralismo y Constitución. Tecnos. Madrid, 2002.

HumboldT, W. Von., Los limites de la acción del Estado. Edit. Tecnos. Madrid, 2002.

—, Escritos de filosofía de la Historia. Edit. Tecnos. Madrid, 1997.

- Sobre la diversidad de la estructura del lenguaje humano. Edit Anthropos. Barcelona, 1990.

—, Escritos sobre el lenguaje. Edit. Península. Barcelona, 1991.

- Sobre el origen de las formas gramaticales y sobre su influencia en el desarrollo de las ideas. Carta a M. Abel Rémusat sobre la naturaleza de las formas gramaticales en general $y$ sobre el genio de la lengua china en particular. Edit. Cuadernos Anagrama. Barcelona, 1972.

LaCAN, J., Escritos. I. Siglo XXI edit. México, 1971.

—, Psicoanálisis. Radiofonía y televisión. Edit. Anagrama. Barcelona, 1977.

LÁzaro Carreter, F., El nuevo dardo en la palabra. Edit. Alianza. Madrid, 2005.

López García, A. y R. Morant, Gramática femenina. Edit. Cátedra. Madrid, 1991.

MONTILla MarTOS, J. A., «Lenguas minoritarias y normalización lingüística ante el Tribunal Constitucional». Revista de la Facultad de Derecho de la Universidad de Granada, n. 5. 2002.

Montoro Chiner, M. J., Adecuación al ordenamiento y factibilidad. Presupuestos de calidad de las normas. CEC. Madrid, 1989.

Puente Ferreras, A., Los orígenes del lenguaje. Edit. Alianza. Madrid, 2006.

Rubio Llorente, F., «El papel del Consejo de Estado en el control de calidad técnica de las normas». En Revista Española de la Función Consultiva, julio/diciembre, 2006.

SAussure, F. de., Curso de lingüistica general. Edit. Losada, S.A. Madrid, 2002.

SuArdiaz, E. D., El sexismo en la lengua española. Edit. Libros Pórtico. Zaragoza, 2002.

TAnnen, D., Género y discurso. Edit. Paidós. Barcelona, 1996.

Teoría y realidad constitucional, n. 2. Segundo semestre. UNED. Madrid, 1998.

TORre, E. y VÁZQUeZ, M. A., Fundamentos de poética española. Edit. Alfar. Sevilla, 1986.

VV.AA., El lenguaje y la mente humana. Edit. Ariel. Barcelona, 2002.

Vernet, J. (coord.), Dret lingüistic. Universitat Rovira i Virgili. Barcelona, 2003.

Violi, P., El infinito singular. Feminismos. Edit. Cátedra. Madrid, 1991.

Wittgestein, L., Tractatus Logico-Philosophicus. Alianza Universidad. Madrid, 1993.

—, Últimos escritos sobre Filosofía de la Psicología. Edit. Tecnos. Madrid, 1996.

—, Estética y hermenéutica. Edit. Tecnos. Madrid, 1996. 
Title

Gender and Language. Proposals for a legal language for gender.

\begin{abstract}
The aim of this paper is to look into the scientific possibilities of the language of gender. It is known that language is expressed in the masculine and ignores gender with the pretension of enclosing women in the masculine gender, comprehensive of the totality of persons.

Thus we have studied language philosophy and the paradigm change which philosophy has experienced since the end of the XIX century. Authors such as Wittgenstein and Gadamer show that language is the principal creator of thinking, and that it is in language that the identity of persons resides. Therefore, the importance of designating women with their particular identity in order to create thinking in their own gender.

A part of social domination is produced in language. Women liberation should also take into account the correct use of language.

The paper proposes legislative reforms in the area of language gender. The laws that protect the equality of women in Spain determine that the language of gender must be used, but there are no safeguard measures as to how you must legislate so that this equality is achieved in the language.

The proposal consists of a law to improve the legislation technique of which the language of gender would form part.
\end{abstract}

\title{
Resumen
}

Este trabajo pretende indagar las posibilidades científicas del lenguaje de género. Es sabido que el lenguaje se expresa en masculino, e ignora la dimensión de género, con la pretensión de englobar a las mujeres en un masculino genérico, comprensivo de la totalidad de las personas. Para ello se ha estudiado la filosofía del lenguaje y el cambio de paradigma que la filosofía experimenta desde finales del siglo XIX. Autores como Wittgenstein y Gadamer, demuestran que el lenguaje es el principal conformador del pensamiento. Y que es en el lenguaje donde reside la identidad de las personas. De ahí la importancia de que las mujeres sean designadas con su particular identidad, para conformar un pensamiento propio de género.

En el lenguaje se produce una parte de la dominación social. La liberación de la mujer también debe tener en cuenta el uso adecuado del lenguaje.

El trabajo propone reformas legislativas en materia de lenguaje de gé- 
nero. Las leyes que protegen la igualdad de la mujer en España, prescriben que se utilice el lenguaje de género, pero no hay previsiones acerca de cómo se debe legislar para que se lleve a cabo con eficacia esa igualdad en el lenguaje.

La propuesta consiste en una ley de perfeccionamiento de la técnica legislativa, de la que formaría parte el lenguaje de género.

\section{Key words}

Women, law, language, domination, liberation, equality.

Palabras clave

Mujer, derecho, lenguaje, dominación, liberalización, igualdad.

\section{Summary}

Previous methodological considerations. I. LANGUAGE. 1. Philosophy and Language. 2. Philology and Language. 3. Anthropology and Language. 4. Language and social domination. II. THE LAW. 1. The language of gender in the law. 2. Legislation technique and the language of gender. 3 . The possibility of a law of legislation technique which integrates the language of gender. 